\title{
Influence of Standard Load Micro- and Nanopatterned in Surface Roughness of bleached Teeth and submitted to Different Surface Treatments
}

\author{
${ }^{1}$ Renata do Amaral Nacanichi, ${ }^{2}$ Mateus Rodrigues Tonetto, ${ }^{3}$ Matheus Coelho Bandéca \\ ${ }^{4}$ Marcelo Ferrarezi Andrade, ${ }^{5}$ José Cláudio Martins Segalla, ${ }^{6}$ Monica Barros Silva \\ ${ }^{7}$ Shilpa H Bhandi, ${ }^{8}$ Fábio Luiz Miranda Pedro, ${ }^{9}$ André Afif Elossais
}

\begin{abstract}
The aim of this study was evaluate the dental enamel after whitening treatment with Opalescence Boost PF ${ }^{\mathrm{TM}} 38 \%$, correlating the structural alterations in the surface of the enamel with its respective $\mathrm{pH}$ and verify if whitened teeth submitted to different finishing and polishing techniques show similar surface texture to healthy teeth (control group). Sixty premolars were divided in 6 groups $(n=10)$, which had been immersed in artificial saliva during all the experiment. Protocol whitening was performed according to the manufacturer recommendations, and then the specimens were submitted to different polishing technique with Sof-Lex Pop On ${ }^{\mathrm{TM}}$ disks, Flex Diamond ${ }^{\mathrm{TM}}$ felt disks using two different micrometric polishing pastes (Enamelize ${ }^{\mathrm{TM}}$ and Diamond Polish ${ }^{\mathrm{TM}}$ ) and two nanometric polishing pastes (Lummina-E Diamond and Lummina-E Alumina), according to the groups. Representative specimens were analyzed in scanning electronic microscopy (SEM). Whitening gel used in this experiment had modified the morphologic aspect of the enamel surface. It was found that two nanometric polishing pastes ( $\mathrm{G} 5$ and $\mathrm{G} 6$ ) promoted a less rough surface compared to control group even after the whitening process.
\end{abstract}

Keywords: Dental enamel, Bleaching, Surface properties, Polishing.

How to cite this article: do Amaral Nacanichi R, Tonetto MR, Bandéca MC, Andrade MF, Segalla JCM, Silva MB, Bhandi SH, Pedro FLM, Elossais AA. Influence of Standard Load Microand Nanopatterned in Surface Roughness of bleached Teeth

\footnotetext{
${ }^{1,9}$ Department of Dentistry, Centro Universitário da Grande Dourados (Unigran), Dourados, Mato Grosso, Brazil

${ }^{2,8}$ Department of Integrated Dentistry Science, University of Cuiabá, UNIC, Cuiabá, Mato Grosso, Brazil

${ }^{3,6}$ Department of Dentistry, CEUMA University, São Luis Maranhao, Brazil

${ }^{4,5}$ Department of Restorative Dentistry, School of Dentistry at Araraquara, UNESP — São Paulo State University, Araraquara São Paulo, Brazil

${ }^{7}$ Department of Conservative Dentistry and Endodontics, MS Ramaiah Dental College and Hospital, Bengaluru, Karnataka India
}

Corresponding Author: Matheus Coelho Bandeca, Head Postgraduate Program in Dentistry, CEUMA University, São Luis, Brazil, e-mail: mbandeca@gmail.com and submitted to Different Surface Treatments. J Contemp Dent Pract 2015;16(3):167-171.

Source of support: Nil

Conflict of interest: None

\section{INTRODUCTION}

Color changes in teeth can be resulting from intrinsic factors coming from congenital causes named fluorosis, enamel hypoplasia, dentinogenesis imperfecta or extrinsic factors, such as smoking, chromogenic substances derived from the diet and other. ${ }^{1}$ To satisfy the expectations of the patient, conservative techniques is preferably indicated with treatments that no require wear on tooth structure, as well as whitening based on hydrogen peroxide or carbamide peroxide, which action mechanism is a reaction by oxidation resulting in fractionation of pigment particles, ${ }^{2,3}$ and uniform whitening of tooth structure.

Indications are according to the techniques and concentration, where it attends the individual needs of each patient. ${ }^{4,5}$ In-office technique is able to whiten teeth faster providing immediate results without the cooperation of the patient, however, high concentration products are required. ${ }^{6}$ At-home technique is necessary to have the discipline of the patient to follow the guidelines for the application and its correct use to achieve satisfactory results. ${ }^{7}$

Due to the intimate contact of the chemical composition of the whitening gel with the tooth surface, it is reported increases porosity and permeability of the enamel, ${ }^{8}$ reducing the resistance to fracture. The surface micromorphology is affected to different degrees, depending on the composition, concentration, time of application and $\mathrm{pH}$ of the gel. ${ }^{4,9}$

Polishing with abrasive disks and polishing pastes can soften the effects caused by whitening on the enamel, where the association of microparticles and the mechanical friction obliterating the depressions and complicating the accumulate plaque, restoring the inherent characteristics of ename. ${ }^{10,14}$

Thus, knowing that the surface texture of the teeth after whitening show morphological changes, the aim of this study is evaluate two nanometer standard pastes 
and check the possibility of returning the original surface characteristics of whitened tooth.

\section{MATERIALS AND METHODS}

Sixty healthy human premolars were selected and stored in saline solution until the beginning of the study. The root of the teeth were included in acrylic resin in PVC mold of $2.5 \mathrm{~cm}$ diameter and $2 \mathrm{~cm}$ in height. The specimens were randomly divided into 6 groups $(n=10)$ (Table 1$)$.

The teeth in groups 2 to 6 were covered by thin layer of $2 \mathrm{~mm}$ thickness of $38 \%$ hydrogen peroxide (Opalesence Boost PFTM, Ultradent Products Inc, Salt Lake City, UT, USA).

\section{Measurement of $\mathrm{pH}$}

Hydrogen potential $(\mathrm{pH})$ of the whitening gel was measured by standardized system (Labmeter digital pH meter, pH 2 model, Serial $\mathrm{N}^{\mathrm{o}}$ 02639) before to the withening treatment, according to Table 2.

\section{Protocols for Surface Treatment}

System of polishing abrasive disks and two abrasive polishers pastes associated with a felt disk were selected for the polishing. According with the group, samples

Table 1: Experimental groups

\begin{tabular}{|c|c|}
\hline Groups & Whitening gel \\
\hline 1. & Control_Artificial Saliva \\
\hline 2. & Opalescence Boost PF TM $38 \%$ \\
\hline 3. & $\begin{array}{l}\text { Opalescence Boost PF }{ }^{\mathrm{TM}} 38 \% \text { + Sof-Lex Pop On }{ }^{\mathrm{TM}}+ \\
\text { Diamond Polish }{ }^{\mathrm{TM}}\end{array}$ \\
\hline 4. & $\begin{array}{l}\text { Opalescence Boost PF }{ }^{\mathrm{TM}} 38 \% \text { + Sof-Lex Pop On }{ }^{\mathrm{TM}}+ \\
\text { Enamelize }^{\mathrm{TM}}\end{array}$ \\
\hline 5. & $\begin{array}{l}\text { Opalescence Boost PF }{ }^{\mathrm{TM}} 38 \% \text { + Sof-Lex Pop On }{ }^{\mathrm{TM}}+ \\
\text { Diamond Polish }{ }^{\mathrm{TM}}+\text { Lummina-E Diamond }\end{array}$ \\
\hline 6. & $\begin{array}{l}\text { Opalescence Boost PF }{ }^{\mathrm{TM}} 38 \%+\text { Sof-Lex Pop On }{ }^{\mathrm{TM}}+ \\
\text { Enamelize }^{\mathrm{TM}}+\text { Lummina-E Alumina }\end{array}$ \\
\hline
\end{tabular}

received surface treatment with different polishing systems after whitening technique described in Table 3.

Specimens (G3 to G6) were finished with abrasive disks (Sof-Lex Pop On ${ }^{\mathrm{TM}}$-3M ESPE) for 30 seconds. Among the disks, the specimens were rinsed with air/water spray to remove residues. After finishing procedure, the specimens were submitted for polishing. The polishing pastes were employed using Flex Diamond ${ }^{\mathrm{TM}}$ felt disks with intermittent movements during 30 seconds.

When the bleaching treatment and polishing were completed, the specimens were sectioned longitudinally and in your cervical limit, so from obtaining the buccal surface as initially performed in preparation of the samples. Then the tooth portions were submitted to Denton Vacuum metal deposition (Desk Model III) for reading on a scanning electron microscope (SEM) system-JEOL ${ }^{\mathrm{TM}}$ (Model JSM-6380LV) in standard increases (1000×).

The criterious for analysis of images performed by SEM was based on the classification of structural changes on the enamel surface, presence of erosions and porosities, as well as the surface texture after finishing and polishing of the experimental groups.

\section{RESULTS}

\section{Group 1 (Control-Artificial Saliva)}

Morphology of enamel presented with irregular surface formed by undulations of the ridges and grooves characteristic of nonprismatic enamel. It can be viewed surfaces with large fissures and grooves as a result of physiological abrasion of toothbrushing (Fig. 1).

Table 2: Experimental groups, $\mathrm{pH}$ and application protocol

\begin{tabular}{llll}
\hline Groups & Whitening gel & $\mathrm{pH}$ & Protocol \\
\hline 1 & Control-Artificial Saliva & 7,00 & - \\
2 to 6 & Opalescence Boost PF Tм & 7,11 & 3 applications with \\
& $38 \% \mathrm{HP}^{*}$ & & 15 minutes \\
\hline
\end{tabular}

$\left.{ }^{*}\right) \mathrm{HP}$ : hydrogen peroxide

Table 3: Materials used for the surface treatment

\begin{tabular}{|c|c|c|c|c|c|}
\hline Material & Classification & $\begin{array}{l}\text { Particle } \\
\text { Abrasive }\end{array}$ & Grit & Manufacturer & Lot / Reference \\
\hline $\begin{array}{l}\text { Sof-Lex Pop } \\
\text { On }\end{array}$ & $\begin{array}{l}\text { Abrasive disks } \\
\text { polyester }\end{array}$ & $\begin{array}{l}\text { Aluminum } \\
\text { oxide }\end{array}$ & $\begin{array}{l}\text { Thick: } 17.10 \mu \mathrm{m} \text { Medium: } 7.10 \mu \mathrm{m} \\
\text { Thin: } 5.72 \mu \mathrm{m} \text { Ultra Thin: } 1.68 \mu \mathrm{m}\end{array}$ & $\begin{array}{l}3 \mathrm{M} \text {-ESPE } \\
\text { Dental Products } \\
\text { St Paul, USA }\end{array}$ & $\begin{array}{l}24054 \\
2380 \mathrm{~B}\end{array}$ \\
\hline Diamond Flex ${ }^{\circledR}$ & $\begin{array}{l}\text { Felt disks with } \\
\text { silicone }\end{array}$ & $\begin{array}{l}\text { Abrasive } \\
\text { none }\end{array}$ & - & $\begin{array}{l}\text { FGM Dental Joinville, } \\
\text { Brazil }\end{array}$ & $\begin{array}{l}010604-6 \\
145\end{array}$ \\
\hline $\begin{array}{l}\text { Diamond } \\
\text { Polish Paste }{ }^{\mathrm{TM}}\end{array}$ & Abrasive paste & Diamond & $0.5 \mu \mathrm{m}$ & $\begin{array}{l}\text { Ultradent Corporation } \\
\text { Chicago, USA }\end{array}$ & $\begin{array}{l}5 \times W 1 \\
998\end{array}$ \\
\hline Enamelize $^{\mathrm{TM}}$ & Abrasive paste & $\begin{array}{l}\text { Aluminum } \\
\text { oxide }\end{array}$ & $0.7 \mu \mathrm{m}$ & $\begin{array}{l}\text { Cosmedent Inc } \\
\text { Chicago, USA }\end{array}$ & $\begin{array}{l}034832 \\
242-4\end{array}$ \\
\hline $\begin{array}{l}\text { Lummina-E } \\
\text { Diamond }\end{array}$ & Abrasive paste & Diamond & $<100 \mathrm{~nm}$ & Experimental Product & - \\
\hline $\begin{array}{l}\text { Lummina-E } \\
\text { Alumina }\end{array}$ & Abrasive paste & $\begin{array}{l}\text { Aluminum } \\
\text { oxide }\end{array}$ & $<100 \mathrm{~nm}$ & Experimental Product & - \\
\hline
\end{tabular}




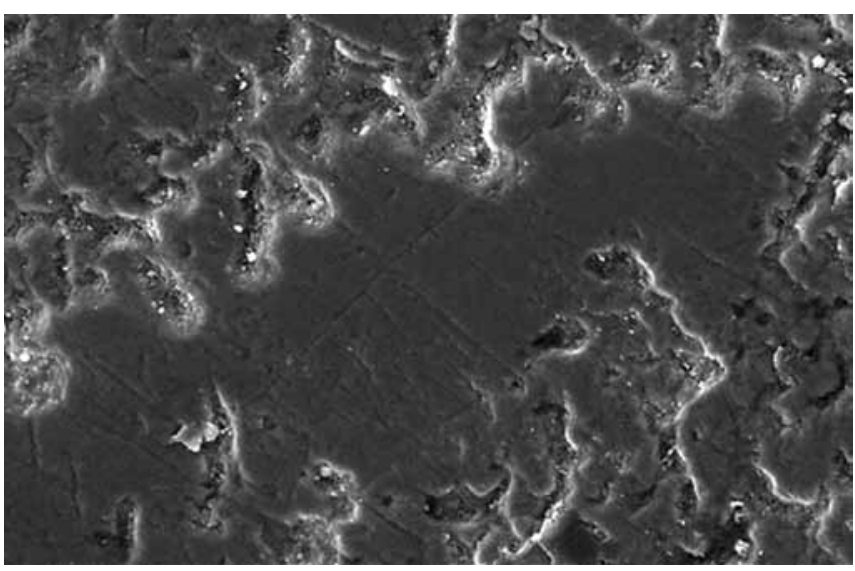

Fig. 1: Surfaces with large fissures and grooves are presented in control group

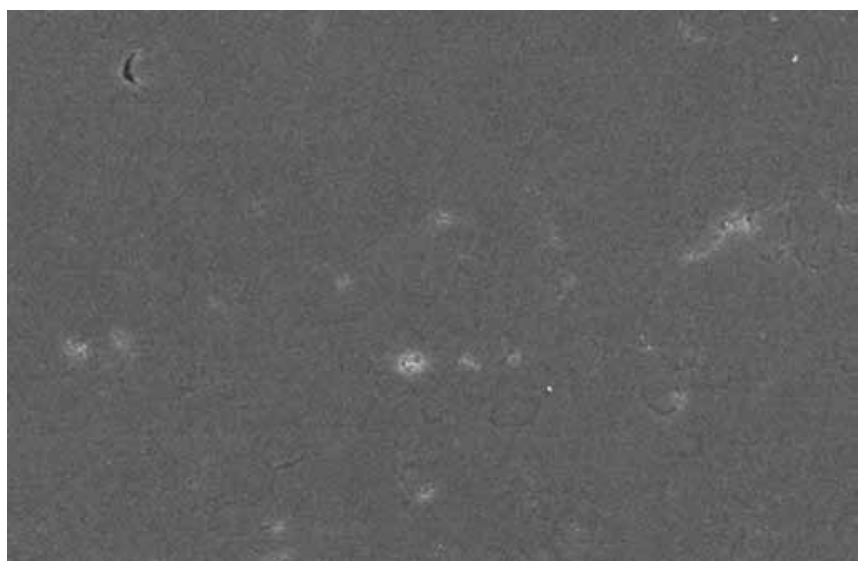

Fig. 3: Risks and grooves were found on enamel surface after polishing with Sof-Lex Pop On ${ }^{\mathrm{TM}}+$ Disk Felt Diamond Flex ${ }^{\mathrm{TM}}+$ Diamond Polish ${ }^{\mathrm{TM}}$

\section{Group 2 (Opalescence Boost PFTM 38\%)}

Enamel showed an irregular surface characterized by the presence of uniform and generalized erosion, with wading depressions giving a peeling appearance due to strong projections (Fig. 2).

\section{Group 3 (Opalescence Boost PFTM 38\% + Sof-Lex Pop On ${ }^{\mathrm{TM}}+$ Diamond Polish $^{\mathrm{TM}}$ )}

Specimens polished using Sof-Lex Pop On ${ }^{\mathrm{TM}}+$ Disk Felt Diamond Flex ${ }^{\mathrm{TM}}+$ Diamond Polish ${ }^{\mathrm{TM}}$ has been found an obliteration of erosions, however, it was noted the presence of risks and grooves (Fig. 3).

\section{Group 4 (Opalescence Boost PF ${ }^{\mathrm{TM}}$ 38\% + Sof-Lex Pop On ${ }^{\mathrm{TM}}+$ Enamelize $^{\mathrm{TM}}$ )}

After polishing with Sof-Lex Pop On ${ }^{\mathrm{TM}}+$ Felt Disk Diamond Flex ${ }^{\mathrm{TM}}+$ Enamelize $^{\mathrm{TM}}$ was observed total obliteration of erosion coming from the whitening process, eliminating the depressions, showing glassy appearance with smooth grooves (Fig. 4).

Group 5 (Opalescence Boost PFTM 38\% + Sof-Lex Pop $\mathrm{On}^{\mathrm{TM}}+$ Diamond Polish ${ }^{\mathrm{TM}}+$ Lummina-E Diamond):

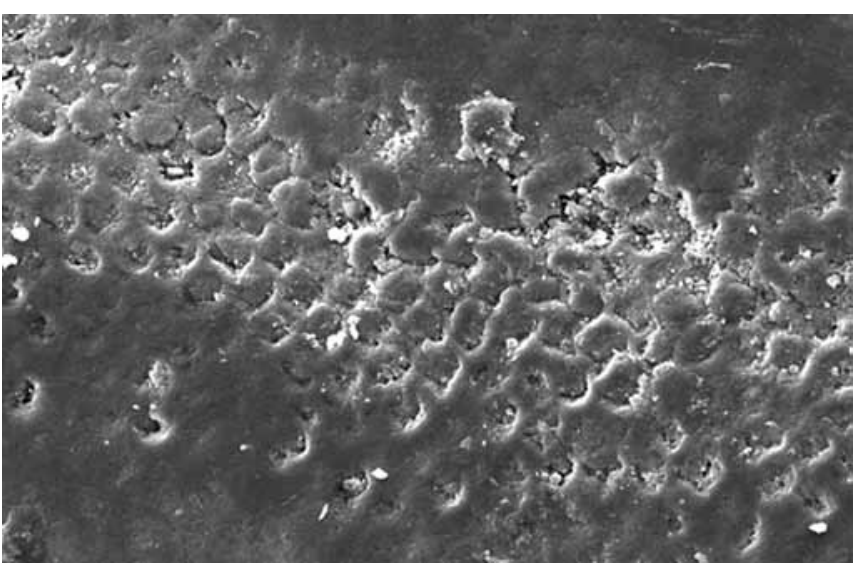

Fig. 2: The surface enamel was irregular with presence of uniform erosion

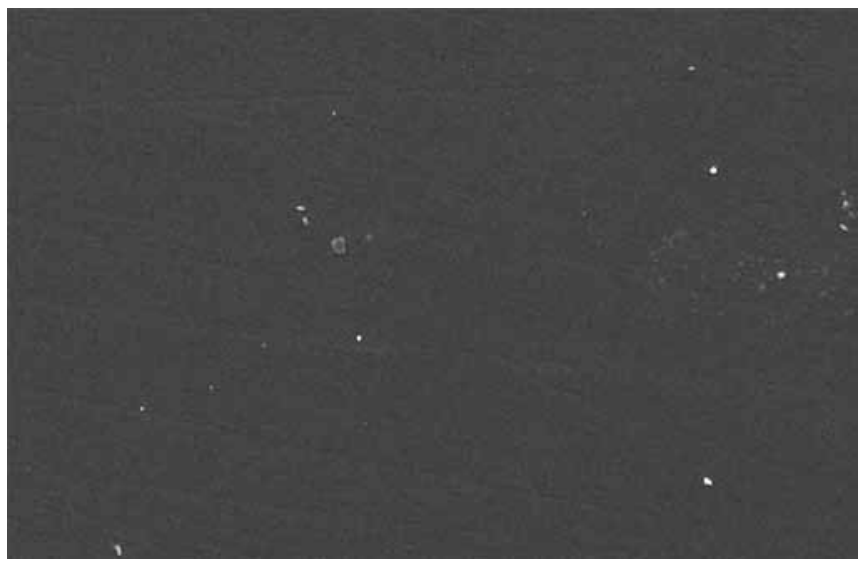

Fig. 4: Obliteration of erosion was found on enamel after polishing with Sof-Lex Pop On ${ }^{\mathrm{TM}}+$ Felt Disk Diamond Flex ${ }^{\mathrm{TM}}+$ Enamelize $^{\mathrm{TM}}$

Specimens polished with Sof-Lex Pop On ${ }^{\mathrm{TM}}+$ Diamond Flex ${ }^{\mathrm{TM}}+$ Lummina-E-Diamond showed a glassy appearance with complete obliteration of erosion, removing deeper risks, however, it was noted the presence of some discrete lines (Fig. 5).

Group 6 (Opalescence Boost PFTM 38\% + Sof-Lex Pop $\mathrm{On}^{\mathrm{TM}}+$ Enamelize $^{\mathrm{TM}}+$ Lummina-E Alumina):

After polishing with disks Sof-Lex Pop On ${ }^{\mathrm{TM}}+$ Diamond Flex ${ }^{\mathrm{TM}}+$ Enamelize + Lummina-E-Alumina, obliteration of erosion was observed coming from the whitening treatment, eliminating the depression and giving a microcrystalline layer, without grooves (Fig. 6).

\section{DISCUSSION}

The results of this research showed that the whitening treatment causes surface changes on enamel. The changes would be more severe if the $\mathrm{pH}$ of the whitening gel deviates more of the neutrality $(\mathrm{pH}=7.0)$. In this research we used the Opalescence Boost $\mathrm{PF}^{\mathrm{TM}} 38 \%$ with a more alkaline $\mathrm{pH}(\mathrm{pH}=7.11)$ that causes lower ionization provide less $\mathrm{H}^{+}$ions to the oxidation reduction reaction, producing less change in tooth surface when compared to other whitening gel. ${ }^{11}$ 


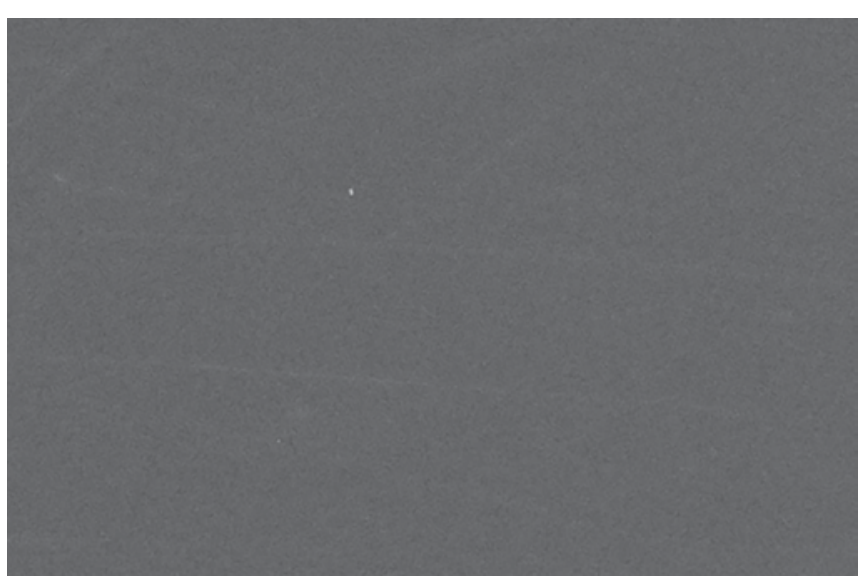

Fig. 5: Some discrete lines were found on enamel after Sof-Lex Pop On ${ }^{\mathrm{TM}}+$ Diamond Flex ${ }^{\mathrm{TM}}$ + Lummina-E-Diamond

In this study, the artificial saliva (G1: $\mathrm{pH}=7,0)$ was used to simulate oral conditions. However, the potential for remineralization is equivalent to the in vivo natural saliva, and fluoride ions in the oral cavity are essential for the balance in the demineralization-remineralization process. $^{12}$

The most severe effect of hydrogen peroxide 38\% was due to the storage of specimens in distilled water; the effects of hydrogen peroxide $38 \%$ in our specimens were probably softened by immersion in artificial saliva.

Scanner electronic microscopy images showed dissolution of the organic layer of enamel surface (G2), but without loss of aprismatic layer, disagreeing of Dominguez et $\mathrm{al}^{13}{ }^{13}$ where there was a dissolution of aprismatic layer and exposure of prisms after long time application of agents with high percentage of hydrogen peroxide. $^{10}$

In relation to the micrometric standard polishing pastes, the Enamelize ${ }^{\mathrm{TM}}$ softened the depressions and erosions coming the whitening. Already Diamond Polish $^{\mathrm{TM}}$ obliterated the depressions and erosions more effectively, however, caused scratches or gouges. The abrasive used in the Enamelize ${ }^{\mathrm{TM}}$ is aluminum oxide $(0.7 \mathrm{mM})$ having Knoop hardness of $2100 \mathrm{~kg} / \mathrm{mm}^{2}$ and the diamond abrasive is Diamond Polish ${ }^{\mathrm{TM}}(0.5 \mathrm{mM})$, which has a Knoop hardness 7000 to $10000 \mathrm{Kg} / \mathrm{mm}^{2}$, much higher than the Knoop hardness of human enamel which is 350 to $380 \mathrm{~kg} / \mathrm{mm}^{2}$, so the occurrence of scratches and grooves after polishing with this polishing paste. ${ }^{14}$

Nanometer standard polishing pastes exhibited a surface texture superior to those images of micrometric standard polishing pastes. For nanotechnology are considers values below 100 units, so the Enamelize ${ }^{\mathrm{TM}}$ $(700 \mathrm{~nm})$ and the Diamond Polish ${ }^{\mathrm{TM}}(500 \mathrm{~nm})$ can not be regarded as such. The prototypes Lummina E-Alumina and Diamond are designed to be within these parameters. ${ }^{15}$

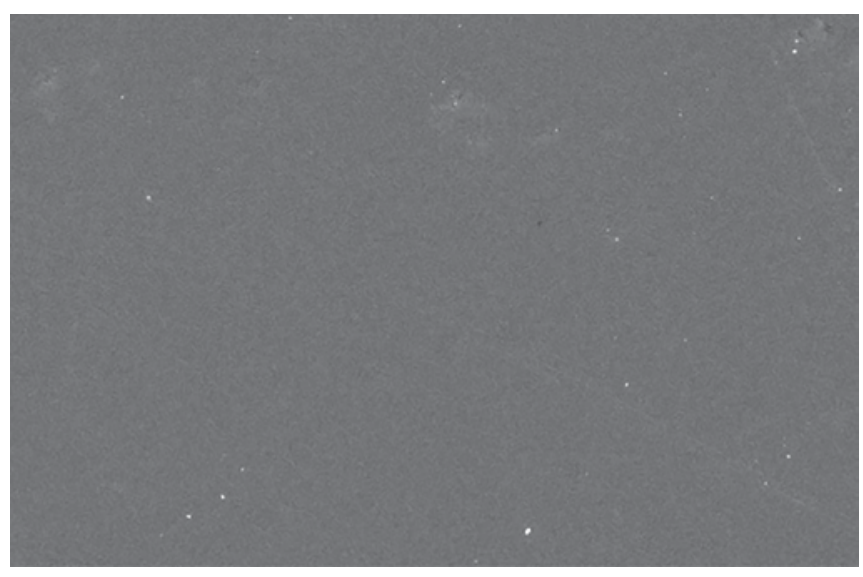

Fig. 6: Total obliteration of erosion was found on enamel after Sof-Lex Pop $\mathrm{On}^{\mathrm{TM}}+$ Diamond Flex ${ }^{\mathrm{TM}}$ + Enamelize + LumminaE-Alumina

Considering erosions presence after the whitening process, this study determined the use of polishing techniques on the surface texture of otherwise healthy tooth enamel. It was noted that this hypothesis was true, since the polishing pastes in nanometer standard (G5 and G6) promoted a less rough surface that otherwise healthy even after the whitening treatment, resulting in a microcrystalline layer.

\section{CONCLUSION}

- The whitening gel used in this experiment altered the morphological appearance of the surface of the tooth enamel and correlation was found between the severity of the changes with the $\mathrm{pH}$ of the same, when compared to the control group.

- The polishing pastes in nanometer standard promoted a less rough surface that otherwise healthy even after the whitening process human enamel.

\section{REFERENCES}

1. Spalding M, Taveira LA, de Assis GF. Scanning electron microscopy study of dental enamel surface exposed to $35 \%$ hydrogen peroxide: alone, with saliva, and with 10\% carbamide peroxide. J Esthet Restor Dent 2003;15(3):154-164; discussion 165.

2. Yeh ST, Su Y, Lu YC, Lee SY. Surface changes and acid dissolution of enamel after carbamide peroxide bleach treatment. Oper Dent 2005 Jul-Aug;30(4):507-515.

3. Pinto CF, Oliveira Rd, Cavalli V, Giannini M. Peroxide bleaching agent effects on enamel surface microhardness, roughness and morphology. Braz Oral Res 2004 Oct-Dec; 18(4):306-311.

4. Cadenaro M, Navarra CO, Mazzoni A, Nucci C, Matis BA, Di Lenarda R, Breschi L. An in vivo study of the effect a 38 percent hydrogen peroxide in-office whitening agent on enamel. J Am Dent Assoc 2010 Apr;141(4):449-454.

5. Bollineni S, Janga RK, Venugopal L, Reddy IR, Babu PR, Kumar SS. Role of fluoridated carbamide peroxide whitening gel in the remineralization of demineralized enamel: An in 
vitro study. J Int Soc Prev Community Dent 2014 May;4(2): 117-121.

6. Oltu U, Gürgan S. Effects of three concentrations of carbamide peroxide on the structure of enamel. J Oral Rehabil 2000 Apr; 27(4):332-340.

7. Moraes RR, Marimon JL, Schneider LF, Correr Sobrinho L, Camacho GB, Bueno M. Carbamide peroxide bleaching agents: effects on surface roughness of enamel, composite and porcelain. Clin Oral Investig 2006 Mar;10(1):23-28.

8. Faraoni-Romano JJ1, Turssi CP, Serra MC. Concentration-dependent effect of bleaching agents on microhardness and roughness of enamel and dentin. Am J Dent 2007 Feb;20(1):31-34.

9. Justino LM, Tames DR, Demarco FF. In situ and in vitro effects of bleaching with carbamide peroxide on human enamel. Oper Dent 2004 Mar-Apr;29(2):219-225.

10. Silva Costa SX, Becker AB, de Souza Rastelli AN, de Castro Monteiro Loffredo L, de Andrade MF, Bagnato VS. Effect of four bleaching regimens on color changes and microhardness of dental nanofilled composite. Int J Dent 2009:313845.
11. Rattacaso RM, da Fonseca Roberti Garcia L, Aguilar FG, Consani S, de Carvalho Panzeri Pires-de-Souza F. Bleaching agent action on color stability, surface roughness and microhardness of composites submitted to accelerated artificial aging. Eur J Dent 2011 Apr;5(2):143-149.

12. Miranda CB, Pagani C, Benetti AR, Matuda Fda S. Evoluation of the bleached human enamel by Scanning Electron Microscopy. J Appl Oral Sci 2005 Jun;13(2):204-211.

13. Dominguez JA, Bittencourt B, Michel M, Sabino N, Gomes JC, Gomes OM. Ultrastructural evaluation of enamel after dental bleaching associated with fluoride. Microsc Res Tech 2012 Aug;75(8):1093-1098.

14. Borges A, Zanatta R, Barros A, Silva L, Pucci C, Torres C. Effect of Hydrogen Peroxide Concentration on Enamel Color and Microhardness. Oper Dent 2014 Aug 19. [Epub ahead of print].

15. Condon JR, Ferracane JL. Reduced polymerization stress through non-bonded nanofiller particles. Biomaterials 2002 Sep;23(18):3807-3815. 